\title{
POST-FOLKLORE AS A PHENOMENON OF COMMUNICATIVE INTERNET PRACTICES
}

\section{Denysiuk Zh. Z.}

\section{INTRODUCTION}

Modern trends in cultural development, which are increasingly affected by the information and communication component, are directly reflected in the socio-cultural practices of everyday life, defining the ideological and value orientations of society. Internet communication, which today is not only a powerful communicative means but also a sign-symbolic environment, accumulates and translates the senses and values that are relevant to society.

The state of social development in conditions of constant transformation and instability, which is marked by many challenges of both global and local level, predetermines value anomy, rethinking, and choosing values that meet the urgent needs and demands of the time. Therefore, a person in such a changing environment is continuously faced with a choice, comprehending the actual events of everyday life in an axiological sense.

Information and communication technologies that have brought dynamic changes in the sphere of interpersonal communication and, in general, social, have led to the creation of the possibility of manifestation of evaluative thoughts and judgments in general, creating with the help of social networks a particular discourse environment. The informal nature of social interaction in the Internet communication environment and the technological possibilities of creating and disseminating information and cultural artifacts form new phenomena which reflect the ideological and value orientations and societal ideals.

Among the phenomena of modern culture, due to their semantic characteristics and innovations fall under the reflection of scientists, the postfolklore deserves particular attention. The beginning of its formation coincides with the processes of urbanization at the end of the XIX century. However, as a qualitatively new segment of the culture, it appears at the end of the XX and especially at the beginning of the XXI century. The process of post-folklore inculcation is mediated using technological reproduction and translation associated with information communication networks.

Modern post-folklore, changing the traditional principles of its creation and transmission, no longer wholly belongs to the cultural examples of folklore in the classical sense of folklore studies. Post-folklore works, being created in a communicative environment using media communication, can organically 
reflect the mosaic socio-cultural reality, including specific ideas, values, and ideals - the axiosphere of culture, acting as a stabilizing beginning regarding comprehending of sociocultural facts.

Scientific research of post-folklore, mediated by communicative practices, was carried out in the aspect of studying digital culture and the socalled "culture of participation," in the works of such scientists as T. Blank, M. Domocos, V. Kravchik-Vasilevskaya, D. Silver, R. Frank, M. Foote, L. Shifman. Post-folklore phenomena of digital culture received a lot of terms of its definition, for example, cyber-folklore, e-folklore, Internet folklore. At the same time, post-folklore of the Internet environment and its genre varieties (memes, demotivators, "doctored picture") are theoretically comprehended in the context of the multimodal discourse of Internet communication. Considerable development has been given to the study of the semantic features of post-folklore texts, contextual relations, graphic, and linguistic components in the design. A special place is given to the study of the phenomena of mimetic and memes as the structure-forming texts of other varieties and genres of post-folklore.

The scientific study of the post-folklore phenomenon is based on the search for the origins of its formation in the urban culture, combined with carnivalized grassroots culture. With the advent of modern communication networks and technologies, the opportunity for users to represent their creativity with the help of electronic tools has resulted in the formation of the postfolklore segment of the Internet environment.

Works of post-folklore within the Internet network include potential recipients in the communicative process, creating opportunities for the exchange of value values, different perceptions of events and phenomena of reality due to the presence of the game component. Deciphering connotations and cultural context in such works serve for further creativity and communicative activity, forme a specific cultural environment of meanings and values as well as is objectified by the constant updating of information in the media space.

At the same time, the post-folklore phenomenon has not yet found theoretical comprehension; it requires cultural research to understand the interaction between post-folklore aspects and modern Internet communication practices which is an integral part of the functioning of cultural values concerning the present. Post-folklore texts accumulate the ideological and value orientations of social and cultural meanings, serve as a source of information for studying the socio-cultural and axiological aspects of the society and its culture development. Mediation of post-folklore by electronic environment allows to analyze the dynamics of current public information, value ideals, and moods of the community as well as to determine its development trends. 


\section{Internet as a universal cultural environment and form of modern communicative practices}

Modern culture is largely determined by the information and communication component and the latest technology which binds together a single means of communication. Thus, new forms of social relations and practices are formed which have already become an integral part of everyday reality and socio-cultural space.

Information and communication technologies and their numerous media communications have created generations of so-called "new media" which based on digital reproduction of information and became the means of performing directly communicative, informational functions, as well as led to the formation of digital cultural phenomena and practices. In fact, the information and technological environment has led to the fundamental transformation of all spheres of social existence, both in practical terms and in aspects of ideological and value relationships, transforming awareness of different levels of human life in the context of the latest media communications. Thus, the medial space in cooperation with the growth of the communicative potential has formed its own semantic and axiological field, creating new ways of symbolic and symbolic development and understanding of the mosaic reality, while applying technological digital tools.

Mass media is a key factor in socio-cultural changes and value strategies of society in the face of the information overpricing of modern society. Being a global communications system, the virtual space of the Internet is a reflection of the most common processes characteristic of modern society. The development of information and communication technologies "squeezes" social space by causing the intensity of information load and qualitative transformation of the dynamics of socio-cultural processes. Intensification of all spheres of society's life, accompanied by technological progress, leads to a violation of the established value-normative unity of society while making it difficult for the cultural self-determination processes to function within the framework of the functioning of the system of ethnocultural values.

The all-encompassing influence of Internet communication has long been an urgent subject of research, given the dynamics of its development, accompanied by constant technological innovations. The Internet environment is a combination of the information and communication and technical component with sociocultural which has become an embodiment and synonymous with the information society and its development - the main factor and speaker of the process of world globalization. Along with the notion of post-industrial society, such concepts as the "global village", "digital society", "network society", and others which are determined by 
network communication, appeared ${ }^{1}$ [7]. The basis of the mentioned studies is the understanding of information and communication as key and determinative factors of progress and development of the human community which is conditioned, first of all, by the growth in the areas of information technology.

Reflecting on the likely development of culture in such a "society of the future," U. Eco noted that the development of human civilization is likely to move to a society with a more significant level of freedom, where free creativity will be present in coexistence with the same free interpretation of texts ${ }^{2}$. [15].

M. Castells, a theorist of the Information Society and Internet Communications who has explored the influence of electronic communications networks on social development in all its spheres, emphasized their that today networks are constituting the fundamental patterns of life. The global networked society is a dynamic structure that is easily influenced by social forces, culture, politics, and economic strategies ${ }^{3}$ [16]. Thus, even at the initial stages of the emergence of computer electronic networks have been represented in numerous reflections of different orientations.

Internet communication, besides purely communicative theories, has led to the formation of discourses of postmodern culture, virtuality, the phenomenon of visual and screen culture, hypertext, etc. Therefore, it is important for us to clarify the features of the functioning of the Internet network and its digital space as a means of modern communicative practices and a universal cultural environment, the semantics of the Internet space and its axiology. After all, they directly influence the formation of works of the postfolklore type in the informational and communicative environment.

The Internet is determined by many scholars as a multi-dimensional technology that combines several media in one environment in which the constant dynamics of change creates opportunities for influence on everyday life. Computer communications have given preference to individual needs and a way of communicative interaction ${ }^{4}$ [19].

The Internet is defined as a cultural form of postmodern, the essential feature of which is its communicative nature from a perspective of the increased

${ }^{1}$ Kaminskaya E.A. (2015). Cultural environment of the modern folklore culture existence. Etnosotsyum. 9, p. 77.

${ }^{2}$ Yugai I.B. (2008). Specificity of communication in cyberspace. Aktualnye problemy socyokulturnyx issledovanyj: mezhregyonalnyj sbornyk nauchnyh statej. Kemerovo. 4, p. 117.

${ }^{3}$ Castells M. (2004). Galaxy Internet: Reflections on the Internet, business and society. Ekaterinburg: «U-Faktory`ya. Gumany`t», p. 38, 43.

${ }^{4}$ Weng L., Menczer F., Ahn Y.-Y. (2014). Predicting Successful Memes using Network and Community Structure. Proceedings of the Eighth International AAAI Conference on Weblogs and Social Media. Pp. 536. 
mosaic, fragmentary, inter- and hypertextual, rituality, the combination of incoherent and the displacement of content ${ }^{5}$ [14].

Internet communication, which today is the most comprehensive channel for the dissemination and exchange of information, has brought a new understanding of communication as such, as well as changed the format of everyday social, including communicative, practices of people. Mobile phones, computers, the Internet, satellite TV, digital video recorders and other technological innovations, have become part of our lives, have changed everyday practices, and with the advent of the Internet, the whole scope of human activity is rapidly being transferred to the communicative space of the global "web". Practices of social communication, information consumption, consumer behavior, educational, entertainment are diversed in terms of content and functional orientation and based on information and communication activities ${ }^{6}[12]$.

Thus, such communication becomes a daily common cultural activity, which is constantly updated, offering new technological devices, their applications, a range of functional services, etc. The informational and communicative and technological components have become important factors in changing the socio-cultural space, introducing new meanings and meanings to it and creating a separate informational and cultural environment, which is described in terms of "virtual", "digital", "digital", "electronic", "cyber" Environment","Internet "and others. The Internet environment by having offered a new communicative and cultural model which has changed the concept of social relationships, the principles of individual identification, representation and creative expression, in fact, the format of existence and ways of representing culture in general.

The Internet network has formed a socio-cultural environment that transforms the perceptions of all areas of social activity and the realities of life. "In the process of humanization the Internet is established as a socially significant space. Its value was determined by the increase in the effectiveness of interaction of individuals within the community, overcoming the spatial restrictions of communication. Particular value is given to the interactive capabilities of the Internet, and it is interactivity that distinguishes the Internet among other media" [28, 89].

The totality and mass distribution of Internet communications was a challenge for established socio-cultural connections and interactions by

${ }^{5}$ Chornovil-Tkachenko R.S. (2006). Theory of Intertextuality: Goals, Problems, Methods. Visnyk SumDU. 11, p. 87.

${ }^{6}$ Radchenko D. Cross-cultural adaptation of the characters of the network folklore: from Hypnozhaba to Zoycha. Antropologycheskyj forum 18. Retrieved from http://www.anthropologie. kunstkamera.ru>files...radchenko.pdf. 
generating new phenomena. Transforming itself from a purely channel and means of communication into a powerful media and cultural environment, the Internet has become a multi-phenomenon for various spheres of social life and individuals. Therefore, in theoretical reflections the Internet is regarded as a cultural and anthropological system phenomenon which includes certain norms and rules (moral, etiquette, aesthetic) ${ }^{7}$ [6].

The medium of existence of the Internet culture is theoretically interpreted in the concepts of "virtual culture", "cyberculture", "digital culture", in each of which indicates the key difference and the peculiarity of the "essence" of this type of culture and its technological substrate. The factors of the formation of cyberculture are the synthesis of technocratic ideas of the developers of computer technology; the ideology of hackers, within which the free circulation of information was postulated; sociological and futurological prophecies of the theorists of postindustrial society; the ideals of marginal subcultures that defended the importance of personal freedom as well as the ideas of economic liberalism ${ }^{8}[13,93]$.

Communicative practices determine the process of the formation of a network culture, which is characterized by a specific spontaneity. The culture of the Internet space is built on the basis of different-level and multi-faceted communicative acts of individuals (non-linear interactions), and the created cultural samples are based both on knowledge and on the virtual-mythological consciousness that is inherent in the worldview of those individuals whose life activity is more or less related to modern information technologies. It is not by chance that the transition to the information type of culture has become a new link in evolutionary development, is primarily associated with the generation of an interactive information and communication environment that influences worldview and cultural structures. Total technological development of the life of a modern person, virtualization of the sociocultural space changes the ways and channels for the exchange of acquired experience, the possibilities of adapting individuals to new conditions, the prospects for creative self-realization.

The modern culture of the Internet environment with a predominant visual component is intensive information flow, acting, in fact, a system of holistic comprehension by a person of the surrounding world in the aggregate of its many-sided manifestations using a sign and a picture. Therefore, visual images provide broad access to the multiplicity of human experience, practice, and behavior.

${ }^{7}$ Ikonnikova S.N. (2008). Postmodernism as a New Paradigm in Culturology. Questions of culturology. 7, 7 .

${ }^{8}$ Strelnik O.N. (2006). Deformation of the language and the mythologization of consciousness in a postmodern culture. Vestnyk RUDN. 2, p. 63. 
One of the ways of presenting the information inherent in modern media is framing - a kind of classification of already existing in the minds of users of background knowledge. In the Internet space, such distribution of any information (which simultaneously updates it for the time being) is recorded and marked with the help of hashtag signs. Therefore, it is possible to create any information reason to attract the attention of other participants of communication and network communities to it.

Another trend of communication in the Internet environment (prevalent in social networks Facebook and Instagram) is the so-called optical micro radiation, which is associated with visual self-documentation on the Internet, thus propagating not only their preferences but also worldview preferences, attitudes, and values. This way of communication is to some extent viral when numerous users of networks record their everyday affairs. In the Internet network all communicants are conditionally interconnected and, as a rule, form communities around specific values and images. With the help of visual images, social roles and hierarchies of values are broadcast. The psychological aspect of this type of communication is the manifestation of one's being and its significance, the desire to receive approval, and the attachment to the values of social success. According to researchers, the media environment creates a field of endless identifications, where a person is fascinated by the images of himself (the ideals of "I"), as an imaginary double, which is created by the screen images given by fashion and advertising ${ }^{9}$. [11]. At the same time, it should be noted that Internet communication increasingly tends to simplify the language of communication, which affects the reduction of the symbolic to the usual graphic designation - "icons" or "smiles."

Becoming a medium provides the implementation of individual cultural practices associated with the pleasure of creative, communicative entertainment and gambling needs, the Internet has opened up opportunities for creating and circulating a segment of artistic creativity based on the semantics of virtual text, coupled with a particular type of consciousness. The latter includes the layer of ordinary knowledge, the desire of the individual, his unconscious instincts, ideas, ideas, images that enable man to exist in a modern technogenic society while preserving his authenticity and individuality ${ }^{10}$ [4]. Thus, as a result, we have cultural samples that, by their content-typological features, the transmission method, relate to post-folklore, which is formed and exists within the information-communicative space of the Internet.

${ }^{9}$ Nazaruk T. (2014) Fakes: the key is not refutation, but the ability to refute. Mediakrytyka. Lviv. Retrieved from http://www.mediakrytyka.info/za-scho-krytykuyut-media/feyky-klyuchovene-sprostuvannya-a-vminnya-sprostovuvaty.html.

${ }^{10}$ Zhigalina O. (2009). Blog as a Hypergenre of Internet Communications. Psykholinhvistyka. 4, pp. 212. 
In traditional folklore as a communicative system in the issue of information transfer, the myth and interpretation were the primary way and medium that filled the message with symbolic codes that needed to be deciphered. That is, the orientation was on the description, the creative interpretation of the narrator. As a result, information in the works acquired such features as variability and plasticity, as the ability to change in the process of communication, passing through the degree of experience and personal attitudes of one's carrier ${ }^{11}$. [1]. In the post-folklore Internet network, such properties of information encoded and broadcast in his works are not only preserved but also greatly enhanced by the digital environment, technologically and meaningfully determines the existence and circulation and distribution of such practices.

The modern format of functioning Post-folklore of the Internet environment with a particular way of organizing visual-verbal sign systems in the context of the studied problems highlights, in fact, the contextual semantic field of the Internet as a cultural and information environment, which is structurally and meaningfully fills the connotational level of works of PostFolklore. From this point of view, it allows analyzing the post-folklore of the Internet product holistically in the unity of the semiosphere and the axiosphere, which arises from the way of coding the actual reality of being. Semantic level of folklore text as a semantic whole and a set of iconic elements, to be punctuated with contextual ethnographic reality, which determines the historical-genetic and ontological creation factors ${ }^{12}$ [5].

Thus, we can sum up that the Internet space is a complex system of communicative and cultural relations, which form a multi-valued environment for the formation and functioning of cultural texts. This environment is a way of symbolic communication, thereby objectifying the reality and expanding the methods of social interaction, is mediated by Internet communication. Communication as a fundamental socio-cultural practice that characterizes the constructive activity of the individual, of course, above all, as the process of creation and reproduction of social reality, where any social connection is based on communication. The environment of Internet communication forms its own semantically axiological field, directly interacts with the system of values of society, it determines it. Consequently, mutual influence leads to a change in peripheral values and established value relationships. The emergence of postfolklore communication as creative expression in social networks of the Internet and virtual consciousness and thinking that operate with symbols, images, mythologems connected with the sign environment of Internet communication,

${ }^{11}$ Bespalova I.V. (2017). The specifics of the Internet as an information and communication medium. Mizhnarodnyy naukovo-doslidnyy zhurnal. 6, p. 80.

${ }^{12}$ Ignatov M.A. (2015). Discourse of Information and Network Culture. Nauka. Yskusstvo. Kul'tura. 2, p. 6. 
formed a segment of post-folklore works, are defined by the semantics of the Internet space and reflects the realities of being, ideas and values in signs and symbols.

\section{Factors and sources of Post-folklore formation, features of its functioning within communicative Internet practices}

In the formation and development of the post-folklore phenomenon, formed in the environment of Internet communication, it is possible to single out objective factors of both technological and socio-cultural nature, which conditioned the mentioned processes.

Communicative activity has become an indicator of technological progress and the overall socio-cultural development of societies, has become far more decisive in changing the cultural paradigm of modernity, where under the influence of the media environment new digital cultural practices are formed, indirectly by communication. The leading place among media agents belongs to the Internet network, which represents virtual information and cultural environment that produces a strictly sign-symbolic field with a particular interpretative and polysemantic character. After all, the media of the postmodern era significantly updated, in fact, the game itself with values where everyone can interpret the message in their way, according to their worldview. "The game in the world of media opens up new horizons for the reality that is being proposed or imposed upon us, where in fact the game itself is a reality" ${ }^{13}$ [9].

Post-folklore, which began to form under the influence of factors of urbanization and the urban environment, acquired new features in the context of the information and communication environment and media communications. Segment of post-folklore, which developed on the Internet as the most "capacious" channel and means of communication, has proved to be quite a widespread phenomenon in the media environment due to the growing number of users and the latest technological capabilities of the format of Internet communication itself.

Due to the technological improvements in Internet communication, the information flow expands, new cultural phenomena appear with the predominance of visual forms of culture that form new narratives. They reflect the permanent process of modernization of society and a qualitative change in everyday practices of human communication. At the same time, it becomes possible for Internet users to distribute their information messages (messages, posts in social networks), visual-graphic works, records, video works, etc., which caused a wave of Internet creativity as a separate segment of culture.

\footnotetext{
${ }^{13}$ Lysyuk N. (2015). Language Wars 2014. Narodna tvorchist` ta etnologiya, p. 26.
} 
The technological substrate in this aspect was the introduction of the web 2.0 platform, which in many ways, in fact, determined the modern "face" of Internet communication: the launch of social networks, the creation, and distribution of users of their content, interactivity of communication - all these factors have become structurally shaping for numerous genre varieties of cultural models of Internet communication and post-folklore. Today, "the Internet functions as a hybrid of the media and interpersonal relations", said the dissertation, American researcher Y. Husted ${ }^{14}$ [18].

The technological possibilities of digital copying and variability of works of the Internet environment have become the critical factors in shaping the nature of communication and communicative practices of everydayentertaining type. Created visual images, graphites soon became rooted in tradition as an integral part of the communicative process of the Internet environment. The organization of the very space of the Internet network, which, along with interactivity, is characterized by such qualities and properties as nonlinearity and hypertext, determined ways of creation and transmission of network texts belonging to post-folklore.

In this context, researchers emphasize the direct dependence of hypertext technologies and nonlinear texts on the result of creative activity, which ultimately leads to a direct dependency of the genre of post-folklore on the way of reading hypertext and the time transmission of information (synchronicity/ asynchrony of communication). As a result, new types of works appear on the Internet network, which is mediated by technological settings and the ability of communicants to use different service programs, while the user can be both the author and the recipient at the same time.

A distinctive feature of the Internet as virtual space is that it is organized in such a way that, with the presence of individual skills, it can be filled with any content. Together with the proliferation of technical devices for receiving and distributing information and the possibility of instant access to the Internet, this creates a situation in which users are induced to fix essential life events, preserving moments that seemed exciting and worthy of being shown to others, and building their texts/works that in game, in a creative form express one or another thoughts and statements, positions, comments/comments. The combination of these factors under the influence of the practical experience of communication caused the creation of the phenomenon of the post-folklore internet network, which is mediated and appears in the process of communicative practices of individuals.

${ }^{14}$ Husted U. M. (2012). A Funny Thing Happened on the Way from the Forum: The life and death of internet memes: a dissertation submitted to the faculty of the graduate school of the university of Minnesota in partial fulfillment of the requirements for the degree of doctor of philosophy, p. 18. 
It should be noted that in general, the emergence of post-folklore became possible to a large extent under the influence of the media and communications, transforming the traditional social and aesthetic forms of cultural practices.

Thus, modern post-folklore performs the same function satisfying the need for comprehension of the events of objective reality, which is carried out at the level of mass consciousness, combined with mythological and stereotypes of perception and reproduction that are capable of a holistic formation of the actual picture of the world with its values, ideals, urgent needs of time.

The ideas of post-folklore texts are partially used by traditional known forms of folklore, mostly verbal forms (anecdote, chatter, fable, etc.), but most of the documents are combined with the visual forms of Internet culture. Accordingly, these types of post-folklore texts are determined by the semantics of the electronic environment. In turn, the cultural environment for post-folklore (in the definition of images, plots) is called folklorism, which reaches traditional folklore and to some extent influences the development of specific genres) ${ }^{15}$. [8]. For example, such a standard type as an anecdote, both in the traditional sense and as a post-folkloric text of Internet communication, is an independent unit that usually does not have definite authorship and is distributed by members of the community or participants in oral or writing connection. Nevertheless, the essential elements and structure must remain unchanged. Post-folklore works, as well as works of traditional folklore, belong to the humorous-laugh format. However, unlike classical patterns, post-folklore texts often comment on events of the current reality.

The Internet environment offers new ways of social interaction and communication that are mediated visually through the exchange of pictures, photos that form a new environment, filled with new meanings and senses. The most common and widespread are social networks, forums, comments under publications, as they allow them to publish their posts, collages, and replicas, which also form a particular informational context. It should also be noted that the anonymity of the Internet provides a wide range of opportunities for the most diverse communication, avoiding traditional established standards, taking over the other roles and identifying oneself, changing the way of thinking and responding. The mentioned factor is also one of the defining elements for characterizing the means of creating and distributing works of the post-folklore type on the Internet.

The collectivity and anonymity of the Internet, the variability of these cultural patterns, the generic a particular environment of the post-folklore communication segment, which is continuously updated, depending on the

${ }^{15}$ Kanashina S.V. (2013). Mem as a unit for the transmission of cultural information by linguistic and non-linguistic means. Vestnyk MHLU. 20, p. 247. 
informational reasons in the media focus, relevant socially significant events that are similar to the topics for Internet users. "The mirror of social and cultural values"16 $^{16}$ [17]. The content texts of post-folklore, which are formed by users of the Internet, reflect the actual reality, which is subject to daily comprehension with the ability to "share" their impressions and thoughts in the process of communication.

If sources of post-folklore as a phenomenon of culture in general, according to the researchers, urban culture and urban folklore, then the definition of the nature and origins of the post-folklore organize a specific cultural space.

The texts of post-folklore, as a whole, and as culture of postmodern, absorb and mosaically reformat all the cultural achievements that are already known, as well as new objects of the present life. The environment of the everyday life is mainly the mass media, subcultures, standards and stereotypes of consumer culture, a segment of the daily news, television, advertising, other exciting events and facts of life, which become the source and thematic content of post- folklore creativity.

Unlike mass culture products, products of post-folklore are not produced for profit, so they are not intended to meet the tastes and needs of a large number of potential users. Therefore, this factor does not affect the nature and quality of the post-folklore, and the creators of such content, do not fight the attention of the recipients, in contrast to the numerous media. Thus, the commercial component in the formation of texts of post-folklore is virtually absent, which makes them spread.

Post-folklore creativity, which belongs to a heterogeneous number of users, allows perceiving post-folklore as a collection of texts. On this basis, there are processes of active, communicative activity, when such contacts are found.

Internet culture, according to researchers, is interconnected with modern culture by such principles as:

- installation of works, which finds in all genres and languages of art;

- due to formats, technical means, and conditions of communication; convenient for modern culture;

- increase the number of messages, in many cases short, replaced by symbols;

- the plurality of texts associated with unlimited storage opportunities, increasing the amount of information, the lack of an identity, the semantic, and value of a selection, when each user of the network saves a lot of personal photos, videos and other information;

${ }^{16}$ Foote M. (2007). Userpicks: Cyber Folk Art in the Early $21^{\text {st }}$ Century. Folklore Forum. Vol. 37.1, p. 34. 
- installation of ready-made messages, data in the completed form ${ }^{17}[10]$.

The mentioned characteristics are acceptable and determining principles for the creation and operation of post-folklore in the information and space areas of the Internet space.

From the perspective of an expanded interpretation of the sociocultural environment, modern post-folklore culture is a set of folkloric practices based, to a certain extent, on the inherent folklore properties: the primitive way of perceiving and experiencing collisions of sociocultural being; reproduction of stylistic folklore features; the predominance of the collective character of communications; the objective embodiment of all sorts of activities in artistic and aesthetic forms. Its structure can be represented as a set of traditional folklore, post-folklore, neo-folklore, and "borderline" phenomena, on an equal footing, include both folklore and other sociocultural constructs. Modern folklore culture actively interacts with other phenomena of the axiosphere of culture, exists in their context. One of them is the cultural environment as an "atmosphere" in which a folk culture exists, develops, transforms.

Such components of the sociocultural environment are the contextual field and source of education Post-folklore, the texts of which absorb the mosaic reality of being by the cultural and spiritual-value demands of the society. Combining various fragments of culture in numerous variations, postfolklore texts, supplemented with laconic phrases, form "Lingvo-cultures of the Internet space, affecting the development of the language and culture of modern society"18 $^{18}$ [3]. Also, the whole linguistic-cultural concepts of post-folklore saturated with cultural connotations and actual values, in a concise form, represent public opinion on current events and life events.

Post-folklore texts are also determined by the basic principles of the creation of postmodern culture, combine its main motives with the components of the current social, cultural and political life. Consequently, a modern collagemosaic culture of the electronic environment is formed, which belongs to the collective authorship, and is the embodiment of free creative expression, value judgments. However, post-folklore can also relate to the relatively regular everyday trends in society, such as the consumer lifestyle, ordinary events.

\section{SUMMARY}

The technological capabilities of the Internet have shaped new models and communication formats that have become an integral part of everyday human practices, bringing a new understanding of the experience of

\footnotetext{
${ }^{17}$ Macaruk L.L. (2014). Problems of the study of semiotically complicated texts. Naukovyj visnyk Cherniveczkogo universytetu. Germanska filologiya. 692-693, p. 71.

${ }^{18}$ Gladkaya N.V. (2017). Logoepistem in the creolized texts of Internet discourse. Visnyk Rosiys'koho universytetu druzhby narodiv. Seriya: Linhvistyka. 2, p. 428.
} 
socialization, value orientations, self-presentation on the Internet, aesthetic and creative expression. Such a segment of contemporary culture as post-folklore, formed in the Internet environment, appears as the embodiment of the nonlinearity, mosaic and intertextuality of modern culture, directly absorbing all the principles of the creation of postmodern culture. The Internet environment, having offered a new communicative and cultural model, changed the perception of social relationships, the laws of individual identification, representation and creative expression. It was this environment that fully ensured the implementation of postmodern carnival freedom, which was expressed in the creation of post-folklore texts.

The texts of post-folklore are based on the values that are divided by a particular society and which express its social ideals. Thus, because of the created post-folklore texts in the process of communicative activity, there is a value-added "balance" between the existential reality and its reflection in ideals or mythological logos.

In a context of transformational social change, ethnic culture continues to perform integrative, communicative, cultivating and educational functions, but in the updated forms. An essential feature of post-folklore is that, as a dynamic type of communication, it is a peculiar mirror of social value change. The works of post-folklore are a means of evaluating self-expression, which is carried through the prism of connotations and representations, connected with various intertextual fragments of culture, which in the end represents integral sign-symbolic formations. Post-folklore texts explode their encoded axiological meanings, which are an expression of an ethnonational component, through the semantic layers of archetypical-mythological structures that reflect the intrinsic values of ethnic culture, world-view, and thinking.

Such aspects of cultural research of the axiological perspective of society make it possible to form the vectors of the development of the information society and culture in the interaction of information and communication technologies and new socio-cultural practices. The presented issues actualize scientific research in the direction of studying the philosophical and ideological foundations of social development, value orientations in the conditions of transformational global transformations, understanding of the artifacts of the digital environment in the cultural space of our time.

\section{REFERENCES}

1. Bespalova I.V. (2017). The specifics of the Internet as an information and communication medium. Mizhnarodnyy naukovo-doslidnyy zhurnal, vol. 6, pp. 80-85 [in Russian].

2. Voroshilova M.B. (2006). Creolized text: aspects of the study. Politychna linhvistyka, vol. 20, pp. 75-89 [in Russian]. 
3. Gladkaya N.V. (2017). Logoepistem in the creolized texts of Internet discourse. Visnyk Rosiys'koho universytetu druzhby narodiv. Seriya: Linhvistyka. Vol. 2, pp. 424-437 [in Russian].

4. Zhigalina O. (2009). Blog as a Hypergenre of Internet Communications. Psykholinhvistyka, vol. 4, pp. 212 [in Russian].

5. Ignatov M.A. (2015). Discourse of Information and Network Culture. Nauka. Yskusstvo. Kul'tura, vol. 2, pp. 70-79 [in Russian].

6. Ikonnikova S.N. (2008). Postmodernism as a New Paradigm in Culturology. Questions of culturology, vol. 7, pp. 4-7 [in Russian].

7. Kaminskaya E.A. (2015). Cultural environment of the modern folklore culture existence. Etnosotsyum, vol. 9, pp. 76-79 [in Russian].

8. Kanashina S.V. (2013). Mem as a unit for the transmission of cultural information by linguistic and non-linguistic means. Vestnyk MHLU, vol. 20, pp. 243-249 [in Russian].

9. Lysyuk N. (2015). Language Wars 2014. Narodna tvorchist' ta etnologiya pp. 23-31 [in Ukrainian].

10. Macaruk L.L. (2014). Problems of the study of semiotically complicated texts. Naukovyj visnyk Cherniveczkogo universytetu. Germanska filologiya, vol. 692-693, pp. 69-72 [in Ukrainian].

11. Nazaruk T. (2014) Fakes: the key is not refutation, but the ability to refute. Mediakrytyka. Lviv. Retrieved from http://www.mediakrytyka.info/zascho-krytykuyut-media/feyky-klyuchove-ne-sprostuvannya-a-vminnyasprostovuvaty.html [in Ukrainian].

12. Radchenko D. Cross-cultural adaptation of the characters of the network folklore: from Hypnozhaba to Zoycha. Antropologycheskyj forum 18. Retrieved from http://www.anthropologie.kunstkamera.ru>files...radchenko.pdf [in Russian].

13. Strelnik O.N. (2006). Deformation of the language and the mythologization of consciousness in a postmodern culture. Vestnyk RUDN, vol. 2, pp. 63-68 [in Russian].

14. Chornovil-Tkachenko R.S. (2006). Theory of Intertextuality: Goals, Problems, Methods. Visnyk SumDU, vol. 11, pp. 82-87 [in Ukrainian].

15. Yugai I.B. (2008). Specificity of communication in cyberspace. Aktualnye problemy socyokulturnyx issledovanyj: mezhregyonalnyj sbornyk nauchnyh statej. Kemerovo, vol. 4, pp. 117-120 [in Russian].

16. Castells M. (2004). Galaxy Internet: Reflections on the Internet, business and society. Ekaterinburg: "U-Faktory`ya. Gumany`t” [in Russian].

17. Foote M. (2007). Userpicks: Cyber Folk Art in the Early $21^{\text {st }}$ Century. Folklore Forum. Vol.37.1, pp. 27-38 [in English].

18. Husted U. M. (2012). A Funny Thing Happened on the Way from the Forum: The life and death of internet memes: a dissertation submitted to the 
faculty of the graduate school of the university of Minnesota in partial fulfillment of the requirements for the degree of doctor of philosophy [in English].

19. Weng L., Menczer F., Ahn Y.-Y. (2014). Predicting Successful Memes using Network and Community Structure. Proceedings of the Eighth International AAAI Conference on Weblogs and Social Media, pp. 535-544 [in English].

Information about the author:

Denysiuk Zh. Z., orcid.org/0000-0003-0833-2993

Doctor of Culturology,

Head of the Research and Publishing Department of National Academy of Culture and Arts Management 9, Lavrska str., Bldg. 15, 01015, Kyiv, Ukraine 